\section{MAKING GOOD SAMARITANS SKILLED SAMARITANS}

R Evens* Correspondence: Golin Harris, Fox Court, 14 Gray's Inn Road, London WC1X 8WS, UK

10.1136/ip.2010.029215.579

Many countries around the world have what is known as a Good Samaritan Law, protecting the rights of those citizens that go out of their way to help those in need, most commonly in emergency situations. This protection may well be a step in the right direction, but does not address the fundamental issue of first aid knowledge. If more people were trained in this life-saving skill, businesses and the general public would have greater confidence in knowing that valuable help was at hand. Up to 150000 people die each year in situations where first aid may have made the difference - four times the number who die each year from the biggest cause of cancer or the equivalent of the entire population of Basingstoke. Our research found that almost two thirds of the general public wouldnt feel confident in administering first aid in an emergency. Even more disturbingly, a quarter would stand by and do nothing, hoping that someone else knows first aid. In spite of these alarming statistics, the UK like many other countries is still guilty of treating first aid as a legislative requirement, rather than a necessary life skill. In communities where medical services might not be easily available, a little first aid knowledge could go a long way. Richard Evens, commercial training director, St John Ambulance, will discuss the importance of first aid knowledge for citizens of all ages, giving examples of where these skills have made a difference between life and death. 